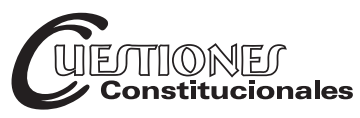

Revista Mexicana de Derecho Constitucional

Núm. 41, julio-diciembre 2019

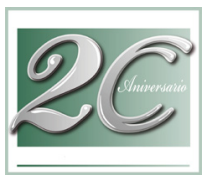

\title{
Configuración de los derechos fundamentales y su contenido esencial en el constitucionalismo ecuatoriano*
}

\author{
Configuration of fundamental rights and their essential content \\ within the Constitution of Ecuador
}

\section{Sebastián LÓPEZ HIDALGO**}

\begin{abstract}
RESUMEN: La configuración del contenido de los derechos fundamentales en el ámbito constitucional es una cuestión de trascendental importancia y depende, de forma directa, de una teoría que la sustenta. Si bien esta temática ha suscitado intensos debates en Europa, fundamentalmente en el último tercio del siglo pasado, la discusión, para el caso ecuatoriano, a pesar de contar con una Constitución renovada, ha sido inexistente. Frente a esta situación, que radica, básicamente, en una incomprensión teórica del problema, el presente artículo, luego de exponer algunas de las teorías más relevantes del contenido de los derechos, así como de una revisión atenta del texto constitucional y de la jurisprudencia existente, concluye que una teoría relativa del contenido esencial, que concibe a los derechos fundamentales en un plano de interrelación constante, es la que me mejor se adapta al modelo constitucional pergeñado en la Constitución de 2008, y cuestiona, al mismo tiempo, la adopción acrítica de una teoría que no ha sido bien comprendida y aplicada en el contexto ecuatoriano.
\end{abstract}

ABSTRACT: The configuration of the contents of fundamental rights in the constitutional arena is an issue of the utmost importance, which directly depends on its underlying theory. Although this topic has been subject of intense debates in Europe, particularly during the last third of the previous century, the discussion in Ecuador is inexistent, despite the emergence of a renewed constitution. Judicial development has, in turn, been inexact. Facing this situation, caused basically by a theoretical misunderstanding of the problem, this article reviews some of the most relevant theories regarding the contents of rights. It then closely analyses the text of the constitution and the existing judicial precedents. The conclusion is that a relative theory of the essential contents of rights, which sees fundamental rights as constantly interrelated, is the most adequate for the constitutional model embodied in the 2008 Constitution. At the same time, the article interrogates the uncritical adoption of a theory that has not been rightly undersroood in the Ecuadorian context.

* El presente artículo, corregido y actualizado, recoge una discusión del trabajo de investigación doctoral de mi autoría con el título: Legitimidad democrática y la tarea interpretativa en la Corte Constitucional del Ecuador, Universidad Andina Simón BolívarQuito, 2016.

** Profesor titular de derecho constitucional en la Universidad del Azuay-CuencaEcuador; docente en la Universidad de Cuenca y en la Universidad Andina Simón Bolívar-Quito; sebaslopezhidalgo@yahoo.com. 
Palabras clave: derechos fundamentales, contenido esencial, derechos, Ecuador.
Keywords: fundamental rights, essential content, rights, Ecuador.

SUMARIO: I. Introducción: el ámbito de configuración de los derechos. II. El contenido esencial de los derechos: teorías, críticas y alcances para el constitucionalismo ecuatoriano.

III. Conclusiones. IV. Bibliografía.

\section{INTRODUCCIÓN: EL ÁMBITO DE CONFIGURACIÓN DE LOS DERECHOS}

Es un tópico frecuente afirmar que el parlamento tiene atribuida la especial competencia para configurar o conformar las disposiciones constitucionales en el marco de un ejercicio de discrecionalidad política.

Esta competencia se relaciona con la facultad de que dispone el legislador para escoger el contenido de las normas entre un amplio número de alternativas políticas de acción, mediante las cuales concreta los enunciados constitucionales con criterios de oportunidad y de conveniencia.

Dicha atribución de competencia se debe, en buena medida, a la calidad que tiene el parlamento como representante de la soberanía popular, así como a la indeterminación semántica de las disposiciones constitucionales sobre derechos que integran el texto fundamental y que, por tanto, necesitan ser concretados mediante medidas legislativas específicas.

Esta concreción resulta conveniente en muchas ocasiones, con el fin de que la fuerza normativa de la Constitución pueda desplegarse de forma plena y efectiva sobre todo el ordenamiento jurídico con capacidad real de transformar la realidad jurídica. Así, la legislación secundaria, respecto de la Constitución, tiene que objetivar los mandatos constitucionales en metas específicas, capaces de armonizar todas las exigencias fundamentales contenidas en preceptos muchas veces abiertos, generales y abstractos.

No obstante, la atribución del parlamento para configurar y concretar el contenido constitucional no significa que las disposiciones previstas en la norma suprema no sean directamente aplicables. Al contrario, "el cumplimiento de los enunciados constitucionales puede exigirse en todo caso, antes, durante y después de la expedición de las leyes que los 
configuran" de forma directa e inmediata. ${ }^{2}$ Es sólo que la "Constitución no vale únicamente en contra de la legislación, sino sobre todo mediante la legislación". ${ }^{3}$

Desde esta óptica, el ámbito de configuración legislativa aparece como uno de los ejes principales del Estado constitucional, en virtud del cual el órgano democrático (parlamento) se erige como la sede natural, aunque no única, en la que se concretan los contenidos constitucionales.

De esta manera, la vinculación del legislador a los derechos fundamentales no es unívoca, sino que se proyecta en una doble vertiente: primero, en una vinculación negativa, que supone la prohibición de cualquier injerencia que no esté autorizada constitucionalmente y, segundo, en una vinculación positiva, que se traduce en el mandato de lograr que los derechos desplieguen toda su eficacia normativa. ${ }^{4}$

Entender las cosas así, por un lado, impone admitir la subordinación y sujeción del legislador a los derechos, pero, por otro lado, autoriza a regular las condiciones de ejercicio de los derechos en un marco normativo lo suficientemente amplio como para que dentro de él quepan opciones políticas de diferente signo. ${ }^{5}$

Consecuentemente, el nexo entre Constitución y legislación queda definido por una tensión que se proyecta en el tiempo. Así, "mientras la

1 Bernal Pulido, Carlos, El principio de proporcionalidad y los derechos fundamentales, Madrid, CEPC, 2005, p. 495.

2 La Constitución ecuatoriana de 2008 - en adelante CRE - en su artículo 11, numeral 3, inciso 1, indica: “...los derechos y garantías establecidos en la Constitución serán de directa e inmediata aplicación por y ante cualquier servidora o servidor público, administrativo o judicial, de oficio o a petición de parte...".

3 Bernal Pulido, Carlos, El principio de proporcionalidad y los derechos fundamentales, cit., p. 495. Igualmente, una referencia normativa a nivel constitucional de este postulado puede verse en el artículo 11, numeral 3, inciso 2, de la CRE que indica: “...para el ejercicio de los derechos y de las garantías constitucionales no se exigirán condiciones o requisitos que no estén establecidos en la Constitución o en la ley...".

4 Medina Guerrero, Manuel, La vinculación negativa del legislador a los derechos fundamentales, Madrid, Mc Graw Hill, 1996, pp. 4-26.

5 El Tribunal Constitucional español, en la sentencia STC 11/1981 del 8 de abril de 1981, fundamento jurídico 7, indicó: "la Constitución es un marco de coincidencias suficientemente amplio como para que dentro de él quepan opciones políticas de muy diferente signo. La labor de la interpretación de la Constitución no consiste necesariamente en cerrar el paso a las opciones o variantes imponiendo autoritariamente una de ellas. A esta conclusión habrá que llegar únicamente cuando el carácter unívoco de la interpretación se imponga por el juego de los criterios hermenéuticos...”. 
legislación concreta en el presente las miras constitucionales de futuro, la Constitución traza el marco de probabilidades de que dispone la política en cada momento histórico". ${ }^{6}$

Pero, además, la cuestión respecto del margen de configuración del contenido de los derechos que tiene el legislador se genera desde el momento en el que las cortes o tribunales disponen también de un ámbito de concreción. ${ }^{7}$ En consecuencia, "ambos —legislador y tribunal - ejercen de manera concurrente pero no idéntica construcción del Derecho en forma de concretización. En esta relación de concurrencia el legislador tiene preferencia, pero, el Tribunal tiene la supremacía". ${ }^{8}$ Ahora, la diferencia más relevante reside en el momento y la orientación del ejercicio de dicha facultad de concreción.

En mayor medida, el ejercicio de la competencia legislativa se realiza con anterioridad a la tarea del control de constitucionalidad, ${ }^{9} \mathrm{y}$ su finalidad consiste en adoptar las cuestiones que en el orden político se consideren más adecuadas para la determinación del contenido de los derechos. Es lo que se ha dado en llamar, de modo genérico, la forma de intervención legislativa. ${ }^{10}$ En términos constitucionales, el legislador cuenta con un amplio margen de maniobra para la configuración de los derechos.

Desde el momento en que toda limitación de los derechos se vincula necesariamente a la finalidad de proteger otro derecho, es claro que la actuación del legislador consiste en dar forma a algunos límites de los derechos fundamentales.

El legislador no crea en realidad el específico límite, sino que lo pone de manifiesto en relación con unos derechos o principios que están en pie

6 Bernal Pulido, Carlos, El principio de proporcionalidad y los derechos fundamentales, cit., p. 496.

7 Como indica Klaus Stern, “....al legislador le corresponde una cierta parte de responsabilidad en el desarrollo de la Constitución, que el Tribunal no pone en duda sino que solamente controla". Véase, Stern, Klaus, Jurisdicción constitucional y legislador, trad. de Alberto Oehling de los Reyes, Madrid, Dykinson, 2009, p. 46.

8 Böckenförde, Ernst-Wolfgang, Escritos sobre derechos fundamentales, trad. de Juan Luis Requejo Pagés e Ignacio Villaverde Menéndez, Baden-Baden, Nomos Verlagsgesellschaft, 1993, p. 130.

9 Se debe destacar en este punto el ejercicio del control de constitucionalidad previo que existe en el ordenamiento jurídico ecuatoriano en el proceso de formación de la ley. Véase los artículos 139 y 438, numeral 3, de la CRE.

10 Bernal Pulido, Carlos, El principio de proporcionalidad y los derechos fundamentales, cit., p. 497. 
de igualdad, ${ }^{11}$ puesto que, como lo anota Medina Guerrero, "insistir en el hecho de que el legislador, al limitar, sólo reproduce unos límites prefigurados ya ex Constitutione no debe, empero, conducir al equívoco de estimar que ésta proporciona ya una ordenación de los límites precisa y cierta; fija e inamovible...". ${ }^{2}$

La Constitución se erige como un marco de ordenación de acuerdo con el cual el órgano legislativo no se convierte en un mero ejecutor, sino que dispone de un amplio margen de configuración dentro del espacio que brindan el ejercicio de otros derechos y bienes constitucionales que entran en juego. ${ }^{13}$

Por su parte, en el ejercicio del control jurisdiccional, la determinación del contenido de los derechos se refiere a un momento posterior a la expedición de la norma, y tiene una finalidad distinta, que consiste en indagar si la norma expedida por el legislador ha transgredido algún derecho o principio fundamental.

En palabras de Rubio Llorente, "la sujeción del legislador a la Constitución y la judicialización de tal sujeción tiene como consecuencia, de una parte, que esa libertad por amplia que se la quiera, haya de tener límites y, de la otra, que esos límites no sean otros que los establecidos por el juez a partir de la interpretación jurídica de los mismos preceptos constitucionales". ${ }^{14}$

Para tal fin, la corte o tribunal también se ve compelido a reducir el marco de indeterminación de las disposiciones constitucionales cuando opera con normas generales, y a enjuiciar la decisión legislativa en cuestión mediante técnicas argumentales idóneas puestas a su disposición.

Lo apuntado hasta aquí muestra una tensión de orden dialéctico entre la competencia de control de constitucionalidad y el ámbito de competencia del legislador que parte de una teoría del contenido de los derechos.

De ahí que "la depuración técnica de la garantía de un contenido esencial en los derechos fundamentales representa, pues, una cuestión de primera importancia para la correcta interpretación y aplicación del texto constitucional". ${ }^{15}$

11 Medina Guerrero, Manuel, La vinculación negativa del legislador a los derechos fundamentales, cit., p. 91.

12 Idem.

13 Idem.

14 Rubio Llorente, Francisco, La forma de poder: estudios sobre la Constitución, Madrid, CEC, 1993, p. 609.

15 Parejo Alfonso, Luciano, "El contenido esencial de los derechos fundamentales en la jurisprudencia constitucional; a propósito de la sentencia del Tribunal Constitu- 
Lo dicho obliga a una breve revisión de las principales teorías que se han ocupado de abordar el significado del contenido esencial, dado que dicho contenido ha sido, tal vez, el criterio más recurrido por la dogmática para intentar definir la vinculación necesaria del legislador democrático y de los poderes públicos a los derechos fundamentales, así como para definir el alcance de la actividad de control de los órganos jurisdiccionales.

Ahora bien, el problema estriba en poder delimitar de manera precisa cuál es el ámbito de dicha garantía, contenida de alguna manera en la Constitución ecuatoriana de 2008 y recogida en la jurisprudencia de la Corte Constitucional ecuatoriana a la luz de las diferentes teorías que sustentan un contenido esencial de los derechos, ${ }^{16}$ cuestionando, por un lado, una adaptación acrítica que ha imperado en el constitucionalismo ecuatoriano, al considerar que los derechos fundamentales contienen un contenido absoluto e inmutable que puede y debe ser definido de manera abstracta en todos los supuestos. Esto evidenciará, además, un problema de definición teórica básica que subyace a las decisiones de la Corte ecuatoriana, en contraposición a la idea originaria instituida por el constituyente en el texto constitucional vigente.

Para ello, se abordarán las diferentes teorías sobre el contenido esencial de los derechos, tratando de identificar cuál de ellas es la que mejor se adapta a un modelo constitucional como el ecuatoriano, que concibe a los derechos fundamentales como sinónimos de derechos constitucionales en un plano de igualdad jerárquica. ${ }^{17}$

cional de 8 de abril de 1981", Revista Española de Derecho Constitucional, núm. 13, 1981, p. 171.

16 El artículo 11, numeral 4, de la CRE dice: "Ninguna norma jurídica podrá restringir el contenido de los derechos ni de las garantías constitucionales", y el numeral 8, en igual sentido, expresa: “...el contenido de los derechos se regulará de manera progresiva a través de las normas, la jurisprudencia y las políticas públicas. El Estado generará y garantizará las condiciones necesarias para su pleno reconocimiento y ejercicio...".

17 A diferencia de lo que podría suceder con otros ordenamientos jurídicos, en el caso ecuatoriano el Constituyente de 2008 ha equiparado el concepto de "derechos fundamentales" al concepto de "derechos constitucionales", dado que no estableció jerarquías entre los derechos reconocidos en la Constitución. Estos derechos fundamentales pueden ser tutelados de forma directa e inmediata, independientemente de si se trata de derechos de primera generación — civiles y políticos- o de derechos de segunda o tercera generación, como pueden ser los derechos económicos, sociales y culturales, e inclusive, derechos de la naturaleza, tal como se encuentra recogido en la carta fundamental. 


\section{EL CONTENIDO ESENCIAL DE LOS DERECHOS: TEORÍAS, CRÍTICAS Y ALCANCES PARA EL CONSTITUCIONALISMO ECUATORIANO}

Ciertamente, un análisis a profundidad de las diferentes teorías del contenido esencial excede las posibilidades y límites de este trabajo. ${ }^{18}$ Consecuentemente, una revisión crítica general de lo que pueden constituir las principales posiciones doctrinales y sus aportaciones para contribuir a precisar cuál es el contenido esencial de los derechos en el texto constitucional ecuatoriano, ${ }^{19}$ así como evidenciar los vacíos y contradicciones existentes dentro del sistema, destacan como los puntos centrales en este apartado.

\section{Teoría absoluta del contenido esencial de los derechos}

La teoría absoluta espacial es aquella que representa a los derechos fundamentales como instituciones estáticas que ocupan un lugar con coordenadas concretas dentro del ordenamiento jurídico. ${ }^{20}$ Definido de esta forma, "el

18 Un estudio de las teorías acerca del contenido esencial puede encontrarse en Gavara de Cara, Juan Carlos, Derechos fundamentales y desarrollo legislativo: la garantía del contenido esencial de los derechos fundamentales en la Ley Fundamental de Bonn, Madrid, CEC, 1994, pp. 23-39.

19 Una referencia al contenido esencial de los derechos sólo puede ser entendida en la actualidad como una consecuencia de la necesidad sentida en Europa, tras la última guerra mundial, de reconstruir la vida social y política sobre principios y valores que impidiesen su degradación hacia totalitarismos estatalitas, y de dotar a los derechos de garantías efectivas, capaces de convertir al propio texto constitucional en un documento resistente frente a su disponibilidad por el propio legislador. Así, la principal desconfianza ante el legislador ordinario es el origen del actual artículo19 de la Ley Fundamental de Bonn, que, entre otros mecanismos de tutela de los derechos fundamentales, sitúa al contenido esencial de los derechos como la garantía frente a toda actividad normativa del legislador que afecte a tales derechos. Dicho artículo ha sido fuente de inspiración del constituyente español de 1978, como se refleja en el artículo 53 de la Constitución Española. Véase esta referencia en Parejo Alfonso, Luciano, "El contenido esencial de los derechos fundamentales en la jurisprudencia constitucional...", cit., pp. 169 y 170. Para algunas importantes referencias sobre la relación entre la legislación alemana y la española respecto de las teorías acerca del contenido esencial, puede verse Martínez Pujalte, Antonio-Luis, La garantía del contenido esencial de los derechos fundamentales, Madrid, Centro de Estudios Constitucionales, 1997.

20 Bernal Pulido, Carlos, El principio de proporcionalidad y los derechos fundamentales, cit., p. 405. 
contenido de los derechos fundamentales se explica a través de un determinado ámbito, en el centro del cual se ubica su núcleo". ${ }^{21}$

Esta teoría sostiene que existe una esfera permanente del derecho que constituye su núcleo esencial e indisponible. Distingue en cada derecho dos partes: una, formada por un núcleo, que vendría a ser el contenido esencial, y otra parte accesoria o no esencial, identificada como la zona de periferia del derecho. La intervención legislativa sólo sería constitucionalmente admisible en la zona periférica o no esencial, pero nunca en el núcleo. ${ }^{22}$

El núcleo del derecho en la teoría absoluta es susceptible de ser definido en abstracto con independencia del caso o de una situación histórica concreta, por lo tanto, irreductible e indisponible por el legislador en cualquier momento. Según esta teoría, el contenido esencial es uno y siempre el mismo, pudiendo ser establecido para cada derecho fundamental en abstracto. ${ }^{23}$

Su núcleo constituye "el reducto último que compone la sustancia del derecho, disuelto el cual (aunque sólo sea en alguno de sus elementos) el derecho deja de ser aquello a lo que la norma fundamental se refiere". ${ }^{24}$ Se trata, por tanto, de un tipo abstracto que preexiste conceptualmente al momento legislativo como una medida establecida y fija, como un elemento estable y definitivo ${ }^{25}$ que debe permanecer siempre, antes y después de cualquier intervención legislativa. Junto a este núcleo inviolable existiría entonces una zona periférica donde el legislador puede ejercer libremente su competencia o configuración legislativa.

Como se ve, sin mayor esfuerzo, podría decirse que, por un lado, la aportación de esta teoría estriba en intentar armonizar la vinculación a los derechos fundamentales que tiene el legislador democrático y su competencia para la configuración legislativa de aquéllos, admitiendo intuitivamente un contenido abstracto y, por otro lado, en determinar que en ningún caso los derechos pueden quedar vacíos de contenido. El contenido nuclear de los derechos para la teoría absoluta es pleno, fijo, inmutable y determinable ex ante.

\section{Idem.}

22 Martínez Pujalte, Antonio-Luis, La garantía del contenido esencial de los derechos fundamentales, cit., pp. 22 y 23.

23 Parejo Alfonso, Luciano, "El contenido esencial de los derechos fundamentales en la jurisprudencia constitucional...", cit., p. 183.

24 Ibidem, p. 180.

25 Gavara de Cara, Juan Carlos, Derechos fundamentales y desarrollo legislativo..., cit., p. 272. 
A pesar de la aportación que brinda esta concepción teórica, en esta visión del ejercicio de los derechos y su contenido, el margen de configuración legislativa queda excesivamente restringido, al trasladar a las cortes o tribunales constitucionales la facultad de determinar mediante una simple actividad deductiva, mecánica y en abstracto, cuál es el contenido de cada derecho, prescindiendo de las exigencias de valoración, ponderación o posible colisión de los derechos en los casos concretos.

Por otro lado, la tarea de determinar el contenido de los derechos en abstracto parece complicada, si se tiene presente que en la mayoría de los textos constitucionales las disposiciones de derechos fundamentales se han enunciado en términos altamente vagos y generales, de modo que no queda absolutamente claro, siempre y en cada momento, cuál es el contenido esencial abstracto de todos los derechos. ${ }^{26}$

Así, la indeterminación que genera la especial imprecisión semántica de los derechos fundamentales vuelve una tarea complicada establecer en abstracto los contenidos de todos los derechos, sin tomar en cuenta las especiales circunstancias que brindan los casos concretos.

Además, una teoría absoluta por definición intuicionista con cada derecho, que deja un excesivo poder de definición y concreción en manos de las cortes y tribunales en desmedro del legislador democrático, favorece la desconstitucionalización del contenido periférico de los derechos por cuanto el legislador, al menos en apariencia, podría quedar librado de cualquier vínculo o control respecto de la parte blanda o zona de periferia del derecho.

Sin embargo, esto sería contrario a las posiciones que defienden una versión clásica de las tesis absolutas, que identificarían siempre y en abs-

26 Para el caso ecuatoriano, aunque la Constitución actual es de aquellas Constituciones de detalle (cuatrocientos cuarenta y cuatro artículos sin contar con sus disposiciones transitorias y otras de naturaleza similar), también incorpora una serie de derechos en forma de cláusulas abstractas y generales, lo que imposibilita su determinación ex ante, en abstracto, de manera definitiva, de un contenido absoluto de cada derecho. Un análisis interesante sobre las paradojas y encrucijadas que presenta el nuevo constitucionalismo latinoamericano y los derechos como normas abstractas puede verse en Rodríguez, Diego, "El nuevo constitucionalismo latinoamericano en la encrucijada: cuatro tendencias y algunos desafíos para el futuro", en Derechos humanos y orden constitucional en Iberoamérica, Civitas, 2011, pp. 147-206. Con otra perspectiva, sobre el nuevo constitucionalismo latinoamericano, puede verse Viciano Pastor, Roberto y Martínez Dalmau, Rubén, “Aspectos generales del nuevo constitucionalismo latinoamericano”, en Ávila, Luis (edit.), Política, justicia y Constitución, Quito, Corte Constitucional del EcuadorCentro de Estudios y Difusión del Derecho Constitucional, 2012, pp. 157 y ss. 
tracto un mismo contenido inmutable y unívoco para todos los casos. Es decir, aun antes de cualquier intervención y configuración del contenido, éste podría y debería ser definido.

De ahí puede deducirse que "una teoría absoluta del contenido esencial no puede decir qué razones superiores no son superiores, sino tan sólo que no existen razones superiores" ${ }^{27}$ dentro del ordenamiento jurídico, puesto que las mismas han venido ya definidas y son plenamente identificables.

Particularmente, para el caso ecuatoriano, con algún matiz, dado que la Constitución contiene una carta especialmente extensa, con una riqueza de formas normativas ${ }^{28}$ que integran derechos con unos contornos más definidos y otros más generales y abstractos, parece no ser apropiada una teoría absoluta del contenido en todos los casos, en razón de que no todos los derechos fundamentales se encuentran en la posibilidad de ofrecer de forma clara, indiscutible, ex ante, un contenido esencial, estático y definitivo que auspicie, además, una deslegitimación apresurada de adaptación política de la norma fundamental. ${ }^{29}$

27 Alexy, Robert, Teoría de los derechos fundamentales, Madrid, CEC, 1993, p. 290. El mismo Robert Alexy indicó: "La convicción de que existen derechos que nunca son desplazados, ni siquiera bajo las circunstancias más extremas - y sólo éstos son derechos absolutos genuinos - puede ser que sea considerada autovinculante para un individuo que tiene la libertad de sacrificarse en aras de determinados principios, pero no puede valer desde el punto de vista del derecho constitucional". Ibidem, p. 291.

28 Como lo sostienen algunos autores: "Sin llegar a ser códigos, las nuevas constituciones se rebelan contra la brevedad, tan aclamada desde la época nominalista... Por su extensión, estas constituciones en alguna medida podrían ser consideradas herederas de la tradicional presencia de textos dilatados y prolíficos...". Véase, Viciano Pastor, Roberto y Martínez Dalmau, Rubén, “Aspectos generales del nuevo constitucionalismo latinoamericano", cit., p. 175. Aun así, estos autores reconocen que las Constituciones del nuevo constitucionalismo latinoamericano son "...esencialmente principistas...", por cuanto “... los principios que abundan en sus textos, en detrimento de las reglas que, aunque presentes, ocupan un lugar limitado a los casos concretos en que su presencia es necesaria para articular la voluntad constituyente...". Ibidem, pp. 173 y 174. Una simple mirada al texto constitucional ecuatoriano confirma lo dicho respecto de la variedad normativa que lo integra: valores constitucionales, normas principios, normas reglas, directrices, encargos al legislador democrático por parte del poder constituyente, están presentes en la Constitución ecuatoriana de 2008 como normas constitucionales.

29 La abstracción no sólo sirve para sortear la objeción contramayoritaria, sino que, además, cuando una Constitución es más detallada y específica, menos apta será para afrontar los problemas de futuro. De ahí que no resulte improbable que este tipo de Constituciones acaben frecuentemente siendo revisadas o reemplazadas por otras. 


\section{Teoría relativa del contenido esencial de los derechos}

La teoría relativa partiría de la constatación de que toda limitación a los derechos fundamentales exige una justificación, la cual puede encontrar un apoyo explícito en la norma constitucional frente a la necesidad de proteger o preservar otros bienes constitucionales. ${ }^{30}$

Para esta teoría, el contenido esencial coincide con una exigencia de justificación, es decir, no existe un contenido abstracto identificable en todo momento y en toda circunstancia para cada derecho fundamental, ya que los derechos poseen igual rango y se relacionan en circunstancias y casos específicos.

Un derecho fundamental, en esta visión, está contenido en una norma constitucional y convive con otras de igual rango y jerarquía, "lo que impone ajustar el contenido de una y otras de forma que ninguna de ellas se vea preterida en su vigencia". ${ }^{31}$

Más allá de que los enunciados constitucionales puedan disponer de un significado prima facie, en la teoría relativa, el contenido esencial es aquello que queda después de un ejercicio de proporcionalidad o ponderación. ${ }^{32}$ No tiene, por tanto, la teoría relativa como punto de partida un contenido que se aprecie como esencial al estilo de una medida preestablecida, fija e inmutable. ${ }^{33}$

Para las teorías relativas, "sería admisible constitucionalmente que en un caso concreto se pudiera realizar una intervención que suponga una inaplicación del derecho fundamental en una situación concreta, siempre que se

30 Martínez Pujalte, Antonio-Luis, La garantía del contenido esencial de los derechos fundamentales, cit., pp. 20 y 21.

31 Véase, Bastidas, Francisco et al., Teoría general de los derechos fundamentales en la Constitución Española de 1978, Madrid, Tecnos, 2004, p. 113.

32 Alexy, Robert, Teoría de los derechos fundamentales, cit., p. 288. Por su parte, dado que el presente estudio pretende una aproximación a la teoría del contenido esencial de los derechos fundamentales en el caso ecuatoriano, un estudio al detalle sobre la aplicación del principio de proporcionalidad como canon de constitucionalidad en la justicia constitucional ecuatoriana y su relación con los derechos fundamentales puede consultarse en López Hidalgo, Sebastián, "El principio de proporcionalidad como canon de constitucionalidad: una aproximación al caso ecuatoriano", Estudios de Deusto: Revista de la Universidad de Deusto, vol. 65, 2017, pp. 185-217.

33 Gavara de Cara, Juan Carlos, Derechos fundamentales y desarrollo legislativo..., cit., p. 272. 
pudiera justificar constitucionalmente". ${ }^{34}$ Es decir, el contenido esencial tiene un valor declarativo, en el sentido de que no es un elemento estable, sino determinable a partir de la propia norma de derecho fundamental en conexión con la justificación de una intervención ${ }^{35}$ en los casos concretos.

Lo anterior implica que a la hora de evaluar la constitucionalidad de un límite impuesto a los derechos fundamentales, el intérprete deba realizar un juicio acerca de la justificación de tal límite o intromisión en el derecho fundamental específico. ${ }^{36}$

Se trataría de una visión "conflictualista del ejercicio de los derechos"37 que es la que se encuentra en la base del juicio de ponderación, y que es la que permite "desarrollar una argumentación más transparente y racional, y con ello también una justificación más adecuada de las decisiones, dado que nos muestra mejor qué es lo que hay que tener en cuenta, esto es, cuáles son las razones en pugna y cómo y por qué nos inclinamos a favor de unas u otras". ${ }^{38}$

Dicha tarea de justificación racional debe ser realizada entonces mediante el principio de proporcionalidad. Así, el contenido constitucional será respetado cuando la limitación se encuentre justificada según la Constitución, de suerte que "garantía del contenido esencial y principio de proporcionalidad se identifican". ${ }^{39}$

Las críticas a esta teoría apuntarían a que mediante una concepción relativa, el contenido esencial del derecho no sería más que una garantía formal y puramente retórica, puesto que admitir que un derecho puede quedar

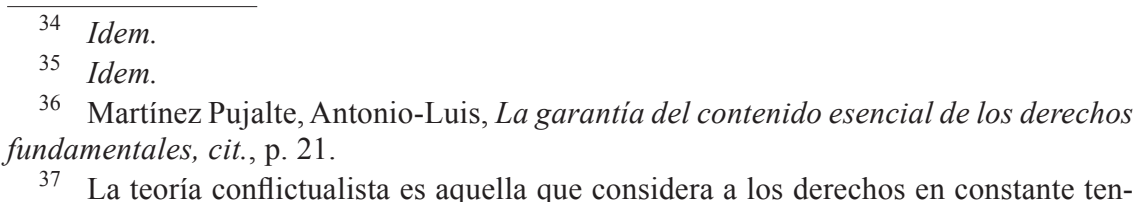
La teoría conflictualista es aquella que considera a los derechos en constante tensión. Reposa en una teoría interna de los derechos y puede alentar un incremento de los mismos y de sus ámbitos de protección, con la consiguiente minimización del poder. Sin embargo, como lo anota Prieto Sanchís, partidarios de los derechos como condiciones absolutas, tales como Ferrajoli, temen que los derechos puedan ser devaluados, perdiendo su fuerza normativa si se los considera en objetos de transacción vía ponderación. Véase, Prieto Sanchís, Luis, "Diez argumentos sobre neoconstitucionalismo, juicio de ponderación y derechos fundamentales", en Ortega y De la Sierra (coords.), Ponderación y derecho administrativo, Madrid, Marcial Pons, 2009, pp. 62 y 63.

38 Idem, p. 64.

39 Martínez Pujalte, Antonio-Luis, La garantía del contenido esencial de los derechos fundamentales, cit., p. 22. 
limitado al amparo de otros bienes constitucionales igualmente protegidos, sin requerir más que un juicio de proporcionalidad de la medida limitadora, equivale a relativizar por completo el carácter jurídico del derecho fundamental, sometiéndolo a permanentes restricciones bajo la fachada de justificaciones proporcionales. ${ }^{40}$

De ahí la tesis difundida en la doctrina acerca de la naturaleza meramente declarativa de la garantía de contenido esencial, que no añadiría nada a la mención constitucional del derecho fundamental, ya que el derecho empezaría donde acaba la posibilidad de limitarlo, pero que ha de permanecer, sin embargo, en la retaguardia del Estado constitucional, para supuestos límites en que aparezcan nuevos peligros para lo esencial de los derechos fundamentales, ${ }^{41}$ reafirmando la limitación del legislador frente a los derechos.

De alguna manera, dado que existen unos derechos con unos contornos más precisos, la Constitución ecuatoriana parece haber tomado este rumbo cuando indica que será inconstitucional cualquier acción u omisión de carácter regresivo que disminuya, menoscabe o anule injustificadamente el ejercicio de los derechos. ${ }^{42}$ Así, una intervención por parte del legislador o de los poderes públicos en el ámbito de los derechos sería justificable si hubiese superado con éxito un test de proporcionalidad.

A pesar de ello, una incomprensión básica de los modelos teóricos que fundamentan la vigencia de una u otra teoría parecería ser el origen del problema en el sistema ecuatoriano.

Y es que también la Corte Constitucional ecuatoriana parece ser cómplice de aquella anunciada incomprensión cuando, moviéndose entre una concepción relativa del contenido de $\operatorname{los}$ derechos ${ }^{43}$ y la teoría absoluta de

\section{Ibidem, p. 28.}

41 Haberle, Peter, "El legislador de los derechos fundamentales", en López Pina, Antonio (ed.), La garantía constitucional de los derechos fundamentales. Alemania, Espana, Francia e Italia, Madrid, Civitas-Universidad Complutense, 1991, pp. 122 y 123.

42 Véase el artículo 11, numeral 8, inciso 2, de la CRE.

43 Véase la sentencia de la Corte 012-09-SEP-CC del 14 de julio de 2009. En dicho fallo, la Corte Constitucional ecuatoriana, refiriéndose al contenido esencial de los derechos, manifestó: "Esta teoría constituye un nuevo paradigma con una interpretación diferente a la habitual (jerarquía, ponderación, subsunción, etc.). Para sus teóricos, los derechos fundamentales son armónicos, constituyéndose en un mito la tan mentada colisión entre derechos, ya que si un derecho es excluido por otro, siguiendo una suerte de darwinismo jurídico, uno de aquellos tiende a depreciarse, lo cual no es susceptible dentro del constitucionalismo, puesto que éste tiende a que los derechos coexistan armónicamente. El punto de partida de la interpretación de los derechos constitucionales debe ser su armo- 
los mismos, ${ }^{44}$ ha indicado que el contenido de los derechos puede variar según el devenir histórico, recalcando que

...es más adecuado no distinguir entre núcleo duro y parte accidental, puesto que el contenido esencial no es el contenido intocable, sino que es determinable con razonabilidad... lo cual evidencia armonización y ajustamiento con otros bienes igualmente humanos y con otras pretensiones igualmente dignas de convertirse en derechos. ${ }^{45}$

Entre una teoría absoluta, escasamente comprendida en sus dimensiones y alcances, y una teoría relativa, el máximo órgano de control constitucional del Ecuador no ha logrado descifrar cuál es la teoría del contenido esencial de los derechos que se adapta fielmente al modelo constitucional ecuatoriano contenido en la Constitución de 2008. Esta situación no sólo ha contribuido a una indefinición de los derechos constitucionales, sino que ha minado la legitimidad del órgano de control encargado de definir el contenido de aquellos derechos en una carta constitucional que se mira garantista.

Sea como fuere, la carga de justificación que pesa sobre el legislador a la hora de limitar-regular los derechos fundamentales en el marco de lo que la propia Constitución establece parece representar una característica común a los sistemas de protección de los derechos, ${ }^{46} \mathrm{y}$ su origen, según P. Sanchís, se encontraría

nía y no su contradicción... Desde el punto de vista de la teoría jurídica de los derechos fundamentales, no es buena técnica establecer limitaciones, jerarquías y balances que prioricen un derecho fundamental sobre otro, ya que lo que se busca es la armonía entre tales derechos... La concepción del contenido esencial considera que es más adecuado no distinguir entre el núcleo duro y parte accidental, puesto que el contenido esencial no es el contenido intocable, sino que es determinable con razonabilidad y que el contenido esencial se delimita desde el bien humano protegido por el derecho, es decir, desde la finalidad del derecho mismo, lo cual evidencia la armonización y el ajustamiento con otros bienes igualmente humanos y con otras pretensiones igualmente dignas de convertirse en derechos".

44 Véase la sentencia de la Corte 009-10-SIN-CC del 09 de septiembre de 2010, en donde la Corte parece adoptar una teoría absoluta del contenido de los derechos, pero también parece orientarse hacia una teoría mixta del contenido esencial.

45 Véase la sentencia referida 012-09-SEP-CC del 14 de julio de 2009.

46 Destacando que no es lo mismo limitación que menoscabo o anulación, el artículo 11, numeral 8, inciso 2, de la CRE dice: "Será inconstitucional cualquier acción u omisión de carácter regresivo que disminuya, menoscabe o anule injustificadamente el ejercicio de los derechos". 
...en la conocida doctrina de la posición preferente de los derechos fundamentales, que supone una inversión de la presunción de constitucionalidad que acompaña habitualmente a los productos del legislador, de manera que cuando este se mueve en la esfera de los derechos es él mismo quien debe destruir la presunción de inconstitucionalidad. ${ }^{47}$

\section{Teoría mixta del contenido esencial de los derechos}

Esta teoría conjuga los postulados básicos de la teoría espacial absoluta con el reconocimiento del principio de proporcionalidad como un elemento integrante de la teoría relativa. Sin embargo, conviene recalcar, desde el inicio, que en esta perspectiva de carácter mixto los derechos fundamentales pueden ser vistos con el mismo esquema de la teoría absoluta.

El matiz que se añade por parte de la teoría mixta es que las intervenciones del legislador en la periferia de los derechos no se encuentran desvinculadas jurídicamente. Dichas intervenciones en la zona de periferia son controlables jurídicamente mediante el principio de proporcionalidad, mientras que el núcleo del derecho debe permanecer inmutable. Lo inmutable sigue siendo el núcleo, pero la periferia estaría siempre sometida a un marco de intervención proporcional. En la doctrina española, L. Parejo, ${ }^{48}$ P. Sanchís ${ }^{49}$

47 Prieto Sanchís, Luis, "La limitación de los derechos fundamentales y la norma de clausura del sistema de libertades", Pensamiento Constitucional, año VIII, núm. 8, 2000, p. 75.

48 Parejo Alfonso, Luciano, "El contenido esencial de los derechos fundamentales en la jurisprudencia constitucional...”, cit., p. 182. Según este autor, "la garantía del contenido esencial está dirigida precisamente a preservar para los derechos fundamentales una concreta e irreductible posición última en ese proceso de determinación del Derecho, de modo que en él el juego de acomodo de los bienes en presencia, y consecuentemente, de precisión de límites encuentra en todo caso, a su vez, un límite final: el del contenido esencial de tales derechos fundamentales". Así, en dicha concreción de límites, el núcleo esencial es irreductible; sin embargo, el margen de periferia sí podría sufrir restricciones.

49 Prieto Sanchís, Luis, Estudios sobre derechos fundamentales, Madrid, Debate, 1990, pp. 142 y ss. De conformidad con Prieto Sanchís, "cabe deducir que la cláusula del contenido no se configura como una exigencia de proporcionalidad entre el sacrificio del derecho y las circunstancias o finalidades que justifican dicho sacrificio, sino como una esfera de intangibilidad que nunca, en ningún caso puede sobrepasarse". Si bien, para Prieto Sanchís, los derechos fundamentales no son ilimitados, debido a que caben ciertas restricciones legislativas sobre los mismos, dicha intervención debe respetar un límite absoluto del contenido esencial, además de estar justificada en términos proporcionales. Es decir, el contenido esencial constituye - para el autor - un parámetro independiente del principio 
y M. Medina Guerrero ${ }^{50}$ cuentan entre los autores más destacados en relación con lo que se podría denominar la teoría mixta del contenido esencial, en la cual, de una u otra manera, enfatizan que la ley debe concretar los indeterminados enunciados constitucionales y precisar las condiciones del ejercicio de los derechos en un amplio margen de libertad para el legislador, limitándolo únicamente por el contenido esencial de los derechos.

Ahora bien, debido a que, por un lado, los defensores de esta teoría parten de un reconocimiento parcial de la teoría absoluta, en el sentido de que identifican un contenido constitucional intangible o inmutable y, por otro, un espacio periférico que se encontraría sujeto a una evaluación de proporcionalidad en parte, las mismas críticas que se vierten contra la teoría absoluta son aplicables a la teoría mixta, ante la dificultad de identificar más allá de un mero intuicionismo, un contenido esencial intangible que en ningún caso puede sobrepasarse.

Puede decirse que la teoría mixta da un paso delante sobre la teoría absoluta, porque reivindica el juicio de proporcionalidad como la medida idónea de evaluación en la zona periférica de los derechos. No obstante, siendo ésta su especial aportación, dicho argumento se convierte precisamente en su mayor debilidad.

Así, la idea de que cada derecho fundamental tiene una zona nuclear que no puede ser restringida "es incompatible por entero con la ponderación entre derechos y bienes y con la aplicación del principio de proporcionalidad; correlativamente, la ponderación y el principio de proporcionalidad son conceptos metodológicamente contradictorios con la idea del contenido esencial, entendido en los términos de la teoría absoluta". ${ }^{51}$

La manera en la que el principio de proporcionalidad y el contenido esencial pueden integrarse en una misma estructura teórica es posible si se

de proporcionalidad. En todo caso, la utilización y justificación que brinda el principio de proporcionalidad sólo sería viable en la zona de periferia del derecho.

50 Medina Guerrero, Manuel, La vinculación negativa del legislador a los derechos fundamentales, cit., p. 170. Para este autor, contenido esencial y principio de proporcionalidad son dos - límites de los límites - de los derechos fundamentales que funcionan de modo independiente. Así, sostendría que "el contenido constitucionalmente protegido (o contenido total) se estructura, en suma, en dos zonas: una central, absolutamente intangible para el legislador (el contenido esencial); y otra externa, que en alguna ocasión hemos dado en denominar (contenido inicialmente protegido) dado que sus integrantes, de carácter claudicante, pueden ser sacrificados por el legislador al objeto de preservar otros derechos o bienes constitucionales siempre que el límite sea proporcionado".

51 Idem. 
piensa que el contenido esencial no es nada distinto a lo que resulta de la aplicación del principio de proporcionalidad, como lo han defendido algunos teóricos. ${ }^{52}$ Por esta razón, el contenido esencial no podría ser identificado ex ante, y sería más bien aquello que se evidencia después de la aplicación del principio de proporcionalidad.

En efecto, una conclusión básica es que mientras la teoría absoluta del contenido esencial observa a cada derecho de forma aislada con un contenido inmutable e invariable, la teoría relativa, con el principio de proporcionalidad por medio y como parámetro de justificación de la restricción, analiza a los derechos en una continua relación dialéctica de unos con otros, más aún si se presentan, como sucede en la Constitución ecuatoriana, en un plano de igualdad jerárquica y de plena justiciabilidad. ${ }^{53}$

La idea de que todo derecho fundamental tiene un contenido esencial inmutable en el que no caben "limitaciones" atendiendo al ejercicio de otros derechos, presupone una observación de los derechos aislados unos de otros. Por esta razón, solamente la teoría relativa se justifica en una Constitución en la que los derechos están en pie de igualdad y en constante interacción.

Además, un exagerado ejercicio cognitivista ha llevado a desplazar el concepto de "limitaciones" constitucionales a los derechos fundamentales por el de "delimitación" 54 interna de los derechos, tratando de suprimir el

52 Alexy, Robert, Teoría de los derechos fundamentales, cit., pp. 288 y 291; Gavara de Cara, Juan Carlos, Derechos fundamentales y desarrollo legislativo..., cit., pp. 272 y ss.; Diez-Picazo, Luis María, Sistema de derechos fundamentales, Navarra, Thomson Civitas, 2008, pp. 123 y 124.

53 Véase el artículo11, numeral 6, de la CRE.

54 Ignacio Villaverde, con algún matiz, ha manifestado: "En rigor habría que decir que los conflictos, si existen, lo son entre el derecho fundamental y sus límites; y en la medida en la que entre sus límites están los derechos fundamentales o constitucionales de terceros, si se puede decir que existen conflictos entre derechos fundamentales. Lo que ocurre es que esta forma de expresarse es engañosa, ya que puede hacer pensar una colisión entre derechos cuando la colisión es entre derecho fundamental y sus límites. Y para ser más exactos, ni siquiera en puridad se puede hablar de colisiones, porque los límites de un derecho fundamental no colisionan con él, sino que justamente sirven para solventar sus posibles colisiones con otros derechos, bienes e intereses". Véase Villaverde, Ignacio, "La resolución de conflictos entre derechos fundamentales: el principio de proporcionalidad", en Carbonell, Miguel (ed.), El principio de proporcionalidad y la interpretación constitucional, Quito, MJDH, 2008, pp. 175 y 176. Igualmente, Ignacio de Otto ha preferido hablar de delimitación de los derechos, asumiendo que "lo que se llama protección de otro bien constitucional no exige en realidad una limitación externa de los derechos y libertades, porque las conductas de las que deriva la eventual amenaza del bien de cuya protección se trata sencillamente no pertenecen al ámbito del derecho fun- 
aparente absurdo que puede significar que el legislador limite un derecho creado por la Constitución, y de soslayar, al mismo tiempo, el tinte negativo que la palabra "limitación" tiene en el mundo de los derechos. ${ }^{55}$

$\mathrm{Al}$ respecto, conviene advertir al menos tres situaciones en el caso ecuatoriano. Primero, la Constitución vigente en ningún momento habla de "delimitación", y, con ello, de una teoría absoluta como si todos los derechos pudiesen brindar de forma clara al intérprete un contenido intocable en abstracto que permita un simple ajustamiento o delimitación. En apoyo de lo dicho puede considerarse, entre otras, la sentencia de la Corte 003-14-SINCC, del 17 de septiembre de 2014, donde la Corte Constitucional ecuatoriana recalca que los derechos fundamentales no tienen el carácter de absolutos, $\mathrm{y}$, en consecuencia, admiten ciertas limitaciones.

Ciertamente, la Constitución actual es clara al manifestar que no cabe "restricción" al ejercicio de los derechos. ${ }^{56}$ Aun así, la Corte Constitucional ecuatoriana, en la sentencia 010-13-SIN-CC del 25 de septiembre de 2013 ha indicado que "...la facultad de configuración legal, que conlleva restricción de derechos constitucionales, debe realizarse en observancia de los crite-

damental y, en consecuencia, no se requiere ninguna limitación de éste para excluirlas". Véase, Otto y Pardo, Ignacio de, "La regulación del ejercicio de los derechos y libertades. La garantía de su contenido esencial en el artículo 53.1 de la Constitución", en MartínRetortillo, Lorenzo y Otto, Ignacio de, Derechos fundamentales y Constitución, Madrid, Civitas, 1988, p. 137. Finalmente, Antonio-Luis Martínez Pujalte también es partidario de este concepto cuando dice: "Lo que se impugna no es, pues, la existencia de los conflictos de derechos, sino su interpretación; y, la que propongo induce a considerar todos los conflictos como aparentes... El proceder adecuado para resolver el aparente conflicto no consiste pues en la determinación del derecho prevalente, ya sea por su superioridad jerárquica general o por su ponderación teniendo en cuenta todas las circunstancias del caso; sino en la delimitación adecuada del contenido de los derechos aducido...". Véase, Martínez-Pujalte, Antonio-Luis, La garantía del contenido esencial de los derechos fundamentales, cit. Ahora bien, conforme lo ha anotado Bernal Pulido, la posición de De Otto y, por extensión, la de quienes siguen esta idea, supone un exagerado credo cognitivista del contenido de los derechos, así como una exagerada posibilidad de analizar las disposiciones fundamentales por métodos lingüísticos, lo cual resultaría inviable. Así, indicó: "según este autor —De Otto—, lo que sucede en realidad es que en estos eventos - de supuesta limitación - la posición jurídica que aparentemente resulta amenazada por ley y cuya restricción estaría justificada por el derecho o bien que respalda la intervención legislativa, no pertenece realmente al ámbito del derecho fundamental supuestamente restringido"; véase, Bernal Pulido, Carlos, El principio de proporcionalidad y los derechos fundamentales, cit., pp. 453 y 454.

55 Bernal Pulido, Carlos, El principio de proporcionalidad y los derechos fundamentales, cit., p. 475.

56 Véase el artículo 11, numeral 4, de la CRE. 
rios de razonabilidad y proporcionalidad...”. Igualmente, la sentencia de la Corte 005-15-SIN-CC, p. 16, del 18 de marzo de 2015, con una referencia a la sentencia de la Corte 010-13-SIN-CC, vuelve a indicar lo mencionado en relación con la restricción. Por otro lado, la misma Corte ha intentado remarcar que una cosa es la regulación y otra cosa es la restricción (Sentencia 003-14-SIN-CC, pp. 40-41, del 17 de septiembre de 2014, referida a la Ley de Comunicación, donde aclara que dicho cuerpo legal regula el ejercicio de los derechos y no restringe los mismos).

De esta manera, se ha dejado abierta la posibilidad de una "regulación", 57 tal como la propia Corte lo ha reconocido en la sentencia 009-10-SIN-CC del 09 de septiembre de 2010, cuando se puso de manifiesto lo siguiente:

Resulta, entonces, que cuando se determina el principio de reserva legal como el establecido en el numeral 8 del artículo 11 de la Constitución, la regulación del mismo no admite otra sino la que debe ser realizada por el Legislador, encargado en última instancia de regular cuidadosamente la materia que es sometida a su conocimiento, en el presente caso, la limitación de los derechos fundamentales en la contratación colectiva reconociendo que la potestad reglamentaria se halla restringida y subordinada. ${ }^{58}$

En igual sentido, la Constitución ha fijado que sólo mediante ley se pueden establecer ciertas limitaciones. Por ejemplo, el artículo 69, numeral 2, de la CRE señala: "Se reconocerá el patrimonio familiar inembargable en

57 En efecto, los artículos 132 y 133 de la CRE, referidos a los principios de reserva de ley ordinaria y orgánica, respectivamente, facultan al legislador a regular el ejercicio de determinados derechos y materias. Puede verse, en ese mismo sentido, por ejemplo, el artículo 66, numeral 22, que dice: "22. El derecho a la inviolabilidad de domicilio. No se podrá ingresar en el domicilio de una persona, ni realizar inspecciones o registros sin su autorización o sin orden judicial, salvo delito flagrante, en los casos y formas que establezca la ley", o el artículo 68, que indica: "La unión estable y monogamia entre dos personas libres de vínculo matrimonial que formen un hogar de hecho, por el lapso y bajo las condiciones y circunstancia que señale la ley...".

58 También puede verse, en materia de control abstracto de normas, las sentencias de la Corte ecuatoriana: 003-14-SIN-CC del 17 de septiembre de 2014, 014-15-SIN-CC del 29 de abril de 2015 y 019-15-SIN-CC del 24 de junio de 2015. Con una referencia al caso español, Blanca Rodríguez anota que la preferencia en el sistema español es la "regulación”, no la imposición de límites al ejercicio de los derechos. No obstante, dice: “...ésta última se asume de forma implícita, en la medida en la que toda regulación del ejercicio de un derecho traza al mismo tiempo e inevitablemente los límites de su ejercicio". Véase, Rodríguez, Blanca, "El caso «Valenzuela Contreras» y nuestro sistema de derechos fundamentales”, Revista Española de Derecho Constitucional, núm. 56, 1999, p. 238. 
la cuantía y con las condiciones y limitaciones que establezca la ley...”; el artículo 66, numerales 17 y 21 , de los derechos de libertad establece: " 17 . El derecho a la libertad de trabajo. Nadie será obligado a realizar un trabajo gratuito o forzoso salvo los casos que determine la ley", "21. El derecho a la inviolabilidad y al secreto de la correspondencia física y virtual; ésta no podrá ser retenida, abierta ni examinada, excepto en los casos previstos en la ley...". Estas reservas habilitan al legislador para fijar con un margen de libertad constitucional la regulación de los límites de un derecho fundamental.

De lo que se trata, en definitiva, es de una "limitación constitucionalmente admisible" cuando de satisfacer otros derechos se trata (lo que se conoce como los límites inmanentes). ${ }^{59}$ Lo que no cabe, en consecuencia, es una "regulación" que vuelva impracticable el ejercicio del derecho o lo dificulte más allá de lo que la propia Constitución pudiese autorizar.

Segundo, el solo hecho de denominar a una intervención legislativa como una actividad de "delimitación" no suprime el riesgo de que el legislador pueda limitar de forma excesiva los derechos. Consecuentemente, sólo tras acometer las valoraciones necesarias mediante el principio de proporcionalidad es posible rechazar una intervención arbitraria y desproporcionada por parte del legislador que debiendo configurar un derecho, en realidad lo desfigura.

Y, tercero, se puede objetar al uso de la palabra "delimitación" su desmedida confianza en una objetividad abstracta del contenido de todos los

59 Los límites inmanentes son aquellos que se derivan de la coexistencia de los derechos fundamentales con otras normas de igual rango constitucional ("límites inmanentes" o "lógicos"). Véase, Bastida, Francisco et al., Teoría general de los derechos fundamentales en la Constitución Española de 1978, cit., p. 139. Por otro lado, como un contraste a los límites inmanentes, los mismos autores se han referido a los límites externos indicando que "su principal característica es que son restricciones que para su establecimiento la Constitución habilita a un poder público, normalmente el legislador. Es por ello que son límites externos, ya que no derivan de la coexistencia del derecho fundamental con otras normas constitucionales o están fijados expresamente por el propio enunciado iusfundamental. La Constitución llama a un poder constituido para que cree esos límites. Así pues, estos límites solo existen si ese Poder constituido los crea. Mientras el habilitado por la Constitución no haga uso del apoderamiento para crear restricciones a los derechos fundamentales, esas restricciones no existen. El límite externo es contingente, $\mathrm{y}$, además, su creación es constitutiva... De modo que no quepa deducir de los enunciados iusfundamentales cláusulas implícitas de limitación externa de los derechos; sin perjuicio de que la Constitución pueda establecer una habilitación general expresa de limitación de los derechos fundamentales (como la contenida en el artículo 19 LFB)". Véase, Bastidas, Francisco et al., Teoría general de los derechos fundamentales en la Constitución Española de 1978, cit., p. 115. 
derechos fundamentales, cuando, en realidad, las disposiciones de derecho fundamental se caracterizan más bien por su indeterminación semántica.

Por lo tanto, si se parte de un modelo de derechos-principios sustanti$\operatorname{vos}^{60}$ y los mismos son considerados como posiciones cerradas, definitivas o absolutas, se llega al resultado de que nunca pueden existir limitaciones legítimas o constitucionalmente admisibles al ámbito de ejercicio de los derechos. Por el contrario, si se parte de un modelo de principios abiertos y generales, es posible una limitación constitucionalmente admisible de un derecho garantizado prima facie por las normas de derecho fundamental que, tras la valoración de cada caso, puede alcanzar el carácter de definitiva. ${ }^{61}$

Junto a ello, pueden ayudar al propósito de concretar el margen de discrecionalidad sobre el alcance del contenido esencial de los derechos, tanto en la sede legislativa como la judicial, un principio de desarrollo progresivo del ejercicio de los derechos con la consecuente prohibición de regresividad, ${ }^{62}$ así como un principio de aplicación más favorable o pro homine y un criterio de interpretación sistemática de la norma fundamental. ${ }^{63}$

En conclusión, una objetividad total únicamente podría alcanzarse en un sistema "ideal" en el que la Constitución pudiese determinar por completo el contenido de cada uno de los derechos que la integran. ${ }^{64}$

Como consecuencia, la función de la corte o el tribunal sería únicamente subsumir los hechos de un caso en el amplio catálogo constitucional disponible, y el parlamento se reduciría al mínimo, encargado únicamente de

60 La expresión "principios sustantivos" es utilizada en el presente trabajo para referirnos a los derechos fundamentales en sí mismos, a diferencia de los denominados "principios de aplicación". Para el efecto, sigo la guía que en el constitucionalismo ecuatoriano ha sido trazada por Ramiro Ávila en su artículo, "Ecuador Estado constitucional de derechos y justicia”, en Constitución del 2008 en el contexto andino, Quito, Ministerio de Justicia y Derechos Humanos, 2008, p. 24. También del mismo autor, el artículo, "Los principios de aplicación de los derechos", en Constitución del 2008 en el contexto andino, Quito, Ministerio de Justicia y Derechos Humanos, 2008, pp. 39-72.

61 Alexy, Robert, Teoría de los derechos fundamentales, cit., p. 271.

62 Sobre este principio, la Corte Constitucional ecuatoriana se ha pronunciado, entre otros casos, en la sentencia 005-13-SIN-CC del 09 de abril de 2013.

63 Véase el artículo 11, numerales 5 y 8 , inciso 1, de la CRE.

64 En relación con las propiedades de un sistema jurídico ideal y coherente o del ideal de una norma perfecta y sus dificultades, puede consultarse Gunther, Klaus, "Un concepto normativo de coherencia para una teoría de la argumentación jurídica", trad. de Juan Carlos Velasco, Doxa: Cuadernos de Filosofía del Derecho, núms. 17-18, 1995, p. 214. 
una mera ejecución de la Constitución, perdiendo todo su significado como espacio ideal de la deliberación democrática.

Sin embargo, ello es imposible, amén de poco deseable, en un Estado con contextos plurales y diversos como el Ecuador. Por esa razón, las cláusulas abstractas de derechos son ideales para una deliberación democrática, y aunque conlleven un margen de discrecionalidad en su aplicación, ello es preferible antes que pretender determinar en abstracto el contenido de unos derechos que deben ser configurados de manera progresiva.

Así, la única teoría compatible con una aplicación del criterio de proporcionalidad capaz de enjuiciar la legítima intervención del legislador en el mundo de los derechos desde un punto de vista positivo es una teoría relativa del contenido de los mismos. Desde esta perspectiva, el contenido de los derechos no constituye una tarea de identificación en abstracto, como supone la teoría absoluta, que limita de entrada las competencias del legislador democrático por suponer un contenido a priori, inmutable y definitivo para cada derecho.

Al contrario, el contenido del derecho debe ser concretado en atención a las específicas circunstancias del caso, lo que requiere la aplicación del principio de proporcionalidad como criterio de control razonable de la tarea legislativa. De esta manera, se justifica también la previsión de la norma fundamental ecuatoriana que consagra positivamente la vinculación del legislador a un contenido de los derechos, abandonando una concepción pasiva de los mismos, tan sólo como límites de los límites a los poderes públicos.

\section{CONCLUSIONES}

La configuración de los derechos fundamentales es una tarea necesaria que cobra un diferente matiz si proviene del legislador o de los órganos jurisdiccionales supremos. De hecho, como se dejó indicado, ambos -legislador y tribunal - ejercen de manera concurrente, pero no idéntica, la construcción del derecho en forma de concretización. Ahora, son las diferentes teorías del contenido de los derechos las que aportan en dicha configuración y concreción.

Así, se ha observado que una teoría absoluta del contenido esencial contempla la idea de una esfera permanente del derecho que constituye su núcleo esencial, un núcleo susceptible de ser definido en abstracto con 
independencia del caso o de una situación histórica concreta, por lo tanto, irreductible e indisponible por el legislador en cualquier momento.

Sin embargo, esta visión de los derechos y su contenido parece una tarea difícil, si se tiene presente que en la mayoría de los textos constitucionales contemporáneos las disposiciones de derechos fundamentales se han enunciado en términos altamente vagos y generales, de modo que no es absolutamente claro, siempre y en cada momento, cuál es el contenido esencial de todos los derechos.

Para el caso ecuatoriano, con una Constitución en la que ciertos derechos aparecen con unos contornos más definidos, y otros más generales y abstractos, no resulta apropiada una teoría absoluta del contenido en todos los casos, en razón de que no todos los derechos fundamentales ofrecen de forma clara un contenido esencial, estático y definitivo.

Por otro lado, la teoría relativa del contenido de los derechos parte de la constatación de que toda limitación a los derechos fundamentales exige una justificación, la cual puede encontrar un apoyo explícito en la norma constitucional ante la necesidad de preservar otros derechos o bienes constitucionales igualmente protegidos.

A pesar de las críticas que enfrenta la teoría relativa, la Constitución ecuatoriana parece haber adaptado sus postulados cuando de forma expresa ha indicado que será inconstitucional cualquier acción u omisión de carácter regresivo que disminuya, menoscabe o anule injustificadamente el ejercicio de los derechos.

Una conclusión básica es que mientras la teoría absoluta del contenido esencial observa a cada derecho de forma aislada, con un contenido inmutable e invariable, la teoría relativa, con el principio de proporcionalidad por medio, analiza a los derechos en una continua relación dialéctica, como sucede en el caso ecuatoriano.

El mayor problema es que la Corte Constitucional no ha sido precisa en su jurisprudencia. Es decir, de manera poco consistente, entre una concepción relativa del contenido de los derechos y la teoría absoluta de los mismos, el órgano de control no ha cumplido con una tarea interpretativa coherente del texto fundamental.

El máximo órgano de control constitucional no ha logrado descifrar cuál es la teoría del contenido esencial de los derechos que se adapta fielmente al modelo constitucional ecuatoriano pergeñado en la Constitución de 2008. 
No existe, en consecuencia, una idea clara de las teorías que podrían sustentar una concepción adecuada de los derechos fundamentales en el constitucionalismo ecuatoriano. Tal como se ha dejado sentando, la Corte ecuatoriana parece desconocer los fundamentos teóricos que sirven de base a sus decisiones.

Pero aún más, si a la incomprensión teórica se suma una discrecionalidad injustificada de los criterios que guían el actuar de la Corte, una apresurada deslegitimación del órgano de control, en perjuicio de un desarrollo de los derechos fundamentales garantizados en la Constitución, parece ser la consecuencia inevitable.

\section{BIBLIOGRAFÍA}

\section{Fuentes bibliográficas}

ALEXY, Robert, Teoría de los derechos fundamentales, Madrid, CEC, 1993.

ÁviLA, Ramiro, "Ecuador, Estado constitucional de derechos y justicia", en Constitución del 2008 en el contexto andino, Quito, Ministerio de Justicia y Derechos Humanos, 2008.

ÁvilA, Ramiro, "Los principios de aplicación de los derechos", en Constitución del 2008 en el contexto andino, Quito, Ministerio de Justicia y Derechos Humanos, 2008,

BASTIDAS, Francisco et al., Teoría general de los derechos fundamentales en la Constitución Española de 1978, Madrid, Tecnos, 2004.

BERnAl PUlido, Carlos, El principio de proporcionalidad y los derechos fundamentales, Madrid, CEPC, 2005.

BÖCKENFÖRDE, Ernst-Wolfgang, Escritos sobre derechos fundamentales, trad. de Juan Luis Requejo Pagés e Ignacio Villaverde Menéndez, Baden-Baden, Nomos Verlagsgesellschaft, 1993.

Constitución de la República del Ecuador de 2008.

DiEZ-PICAzO, Luis María, Sistema de derechos fundamentales, Navarra, Thomson Civitas, 2008.

GaVARA DE CARA, Juan Carlos, Derechos fundamentales y desarrollo legislativo: la garantía del contenido esencial de los derechos fundamentales en la Ley Fundamental de Bonn, Madrid, CEC, 1994. 
GUNTHER, Klaus, "Un concepto normativo de coherencia para una teoría de la argumentación jurídica", trad. de Juan Carlos Velasco, Doxa: Cuadernos de Filosofía del Derecho, núms. 17-18, 1995.

HÄBERLE, Peter, "El legislador de los derechos fundamentales", en LÓPEZ PINA, Antonio (ed.), La garantía constitucional de los derechos fundamentales. Alemania, España, Francia e Italia, Madrid, CivitasUniversidad Complutense, 1991.

LóPez Guerra, Luis, Las sentencias básicas del Tribunal Constitucional, 3a. ed., Madrid, Centro de Estudios Políticos y Constitucionales, 2008.

LóPeZ Hidalgo, Sebastián, "El principio de proporcionalidad como canon de constitucionalidad: una aproximación al caso ecuatoriano", Estudios de Deusto: Revista de la Universidad de Deusto, vol. 65, 2017.

MARTínez PujALTE, Antonio-Luis, La garantía del contenido esencial de los derechos fundamentales, Madrid, CEC, 1997.

MEDINA GUERRERO, Manuel, La vinculación negativa del legislador a los derechos fundamentales, Madrid, Mc Graw Hill, 1996.

OTTO Y PARDO, Ignacio de, "La regulación del ejercicio de los derechos y libertades. La garantía de su contenido esencial en el artículo 53.1 de la Constitución", en MARTíN-RETORTILlo, Lorenzo y OTTO, Ignacio de, Derechos fundamentales y Constitución, Madrid, Civitas, 1988.

PAREJO AlfOnSO, Luciano, "El contenido esencial de los derechos fundamentales en la jurisprudencia constitucional; a propósito de la sentencia del Tribunal Constitucional de 8 de abril de 1981", Revista Española de Derecho Constitucional, núm. 13, 1981.

PRIETO SANCHÍs, Luis, "Diez argumentos sobre neoconstitucionalismo, juicio de ponderación y derechos fundamentales", en ORTEGA y DE LA SIERRA (coords.), Ponderación y derecho administrativo, Madrid, Marcial Pons, 2009.

PRIETO SANCHÍS, Luis, "La limitación de los derechos fundamentales y la norma de clausura del sistema de libertades", Pensamiento Constitucional, año VIII, núm. 8, 2000.

PRIETO SANCHÍs, Luis, Estudios sobre derechos fundamentales, Madrid, Debate, 1990. 
RODRÍGUEZ, Blanca, "El caso «Valenzuela Contreras» y nuestro sistema de derechos fundamentales", Revista Española de Derecho Constitucional, núm. 56, 1999.

RODRÍGUEZ, Diego, "El nuevo constitucionalismo latinoamericano en la encrucijada: cuatro tendencias y algunos desafíos para el futuro", en Derechos humanos y orden constitucional en Iberoamérica, Civitas, 2011.

RUBIO LlORENTE, Francisco, La forma de poder: estudios sobre la Constitución, Madrid, CEC, 1993.

STERN, Klaus, Jurisdicción constitucional y legislador, trad. de Alberto Oehling de los Reyes, Madrid, Dykinson, 2009.

Viciano PASTOR, Roberto y MARTínez DalmaU, Rubén, “Aspectos generales del nuevo constitucionalismo latinoamericano", en ÁVILA, Luis (edit.), Política, justicia y Constitución, Quito, Corte Constitucional del Ecuador-Centro de Estudios y Difusión del Derecho Constitucional, 2012.

VILLAVERDE, Ignacio, "La resolución de conflictos entre derechos fundamentales: el principio de proporcionalidad", en CARBOnELL, Miguel (ed.), El principio de proporcionalidad y la interpretación constitucional, Quito, MJDH, 2008.

\section{Fuente jurisprudencial}

Sentencia de la Corte Constitucional del Ecuador 003-14-SIN-CC del 17/09/2014.

Sentencia de la Corte Constitucional del Ecuador 005-13-SIN-CC del 09/04/2013.

Sentencia de la Corte Constitucional del Ecuador 005-15-SIN-CC del $18 / 03 / 2015$.

Sentencia de la Corte Constitucional del Ecuador 009-10-SIN-CC del 09/09/2010.

Sentencia de la Corte Constitucional del Ecuador 010-13-SIN-CC del 25/09/2013.

Sentencia de la Corte Constitucional del Ecuador 014-15-SIN-CC del 29/04/2015. 
Sentencia de la Corte Constitucional del Ecuador 019-15-SIN-CC del 24/06/2015.

Sentencia de la Corte Constitucional del Ecuador 009-10-SIN-CC del 09/09/2010.

Sentencia de la Corte Constitucional del Ecuador 012-09-SEP-CC del 14/07/2009.

Sentencia STC 11/1981 del Tribunal Constitucional español.

Fecha de recepción: 08 de noviembre de 2017.

Fecha de aceptación: 01 de septiembre de 2018. 